\title{
Visión de la comunidad estudiantil del bachillerato en Villa Hidalgo, Jalisco
}

Hugo Barrera Chávez, Humberto Atilano Calvillo, Felipe de Jesús Moreno Saucedo y Melissa Sarahi Sandoval Picazo

\section{Resumen}

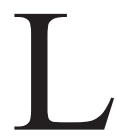

a visión de los jóvenes de bachillerato necesita ser percibida desde el entorno en el que se desarrollan, de esta manera se podrían plantear estrategias de intervención que les permitan egresar del nivel medio superior. Por lo tanto, se necesitan conocer los factores contextuales que influyen para que los alumnos de bachillerato en el municipio de Villa Hidalgo, Jalisco, tomen una decisión sobre seguir en su trayectoria académica. Para tal finalidad, se realizó un estudio que se aplicó a un total de 120 alumnos de sexto semestre, pertenecientes a la Preparatoria Regional Lagos de Moreno, módulo Villa Hidalgo, para comprender las principales motivaciones y aspectos socioculturales, por los que determinan continuar estudiando o no. El 73\% de los jóvenes mencionaron que sí desean ingresar a la universidad, $72.89 \%$ señala que la razón principal para no continuar es la escasez de recursos económicos, además del apoyo brindado por las familias.

Palabras clave: visión, nivel medio superior.

\section{Introducción}

En general, la escuela contribuye a la constitución de las capacidades sociales en un momento, contexto y condiciones específicos, aportando de manera significativa en la vida social de los alumnos, dentro y fuera de la escuela (Bustamante, 2014). En particular, el nivel medio superior tiene como fin desarrollar ciudadanos participativos que acrecienten el patrimonio científico tecnológico, humanístico y artístico de México (Guerra, 2000). Por lo tanto, para lograr proveer a los alumnos con estas facultades, en febrero de 2012 la educación media superior se vuelve obligatoria para todos los jóvenes, debido a lo anterior, se volvió necesaria una reestructuración del modelo educativo. Esto último implicó un análisis exhaustivo para redefinir los programas de estudio, por consiguiente se creó el Marco Curricular Común (MCC) (Ibarra, Escalante y Fonseca, 2013). Con la implementación del MCC se buscó que cada vez más jóvenes permanecieran, concluyeran su bachillerato y pudieran seguir con su educación universitaria; sin embargo, a pesar de los esfuerzos, esto representa una tarea difícil, ya que los estudiantes no pueden culminar e ingresar al siguiente nivel educativo debido a diferentes factores (Ruiz, García y Pérez, 2014; Valdez, Román, Cubillas y Moreno, 2008).

Ingresar a la universidad generalmente es visto por los estudiantes y sus familiares como una gran oportunidad de superación personal, movilidad económica y una herramienta necesaria dado el contexto social en que se vive actualmente, sin embargo, esto implica fuertes cambios sociales y económicos; a pesar de la importancia

Ingresar a la universidad generalmente es visto por los estudiantes y sus familiares como una gran oportunidad de superación personal. \》 
que representa el ingreso a los estudios superiores y la recompensa económica que puede generar, un gran número de personas toman esta decisión de acuerdo a su entorno social y familiar, es decir, condicionan su elección dependiendo de la solvencia económica, intereses y situaciones personales (Sifuentes y Lera, 2017; Smulders, 2018).

En el municipio de Villa Hidalgo, Jalisco, resulta difícil que el estudiante del último semestre de bachillerato entienda los beneficios para su vida profesional y laboral de una carrera universitaria, de acuerdo a la situación que predomina en la localidad. Esta localidad es uno de los 125 municipios de dicho estado, se localiza en la Región Altos Norte, con aproximadamente 20,250 habitantes (Instituto de Información Estadística y Geográfica de Jalisco [IIEG], 2018). Dentro de sus actividades económicas se encuentran: la agricultura, ganadería, construcción casahabitación e industria textil, siendo todo lo que se encuentra en torno a esta última la ocupación de más peso en Villa Hidalgo, además constituye una de las razones que condicionan la migración del nivel medio superior al superior. Por lo anterior, resulta necesario conocer la visión y las problemáticas que tienen que superar los estudiantes para tal fin, de tal manera, este trabajo tuvo como objetivo analizar lo que piensan los alumnos del sexto semestre de la Escuela Preparatoria Regional de Lagos de Moreno, módulo Villa Hidalgo, así como las causas que les impiden realizar una carrera universitaria.

《 En el municipio de Villa Hidalgo, Jalisco, resulta difícil que el estudiante del último semestre de bachillerato entienda los beneficios para su vida profesional y laboral de una carrera universitaria. $\gg$

\section{Factores que influyen en la decisión de ingreso a educación superior}

VISIÓN SOBRE LA EDUCACIÓN SUPERIOR

Los alumnos de bachillerato
reconocen la importancia de la
educación superior en su futuro, ya
que lo ven como una vía
importante para mejorar sus
ingresos económicos

《 Los estudiantes de Villa Hidalgo, Jalisco, hoy en día consideran la preparación escolar como una prioridad en su vida. \

Se realizaron dos encuestas a un total de 120 alumnos, correspondientes a los cinco grupos de sexto semestre de esta institución con 25 reactivos cada una, en los meses de febrero a marzo del 2019. En la primera se buscaba conocer cuál era el porcentaje de alumnos que deseaban seguir con sus estudios universitarios, y en la segunda las causas que truncan su trayecto a ese nivel educativo.

La mayoría de los estudiantes a los que se les aplicó la encuesta, reconocen la importancia de la educación superior, en concordancia con lo anterior, $73 \%$ de los jóvenes mencionaron que sí desean ingresar a la universidad. De esos alumnos, $51 \%$ sostuvo que para ellos resulta de gran importancia el continuar con su vida académica, ya que es menester para su futuro, un porcentaje igual, señaló que ya había realizado trámites (en los meses en los cuales se realizó el estudio) para la o las universidades de su elección. El 55\% mencionaron que estaban acudiendo a cursos o estudiando por cuenta propia para garantizar su entrada a alguna universidad, asimismo, externaron encontrarse motivados ante esa posibilidad (84\%), puesto que, piensan que es una manera de generar buenos ingresos en su vida futura (68\%).

En contraposición a los resultados obtenidos, está el hecho de que la industria textil genera gran cantidad de trabajos durante los meses de octubre a diciembre, en lo que ellos llaman "la Temporada", que van desde empleados de mostrador y bodega, vendedores de piso, hasta cui-

\section{CAUSAS QUE AFECTAN LA CONTINUACIÓN DE ESTUDIOS}

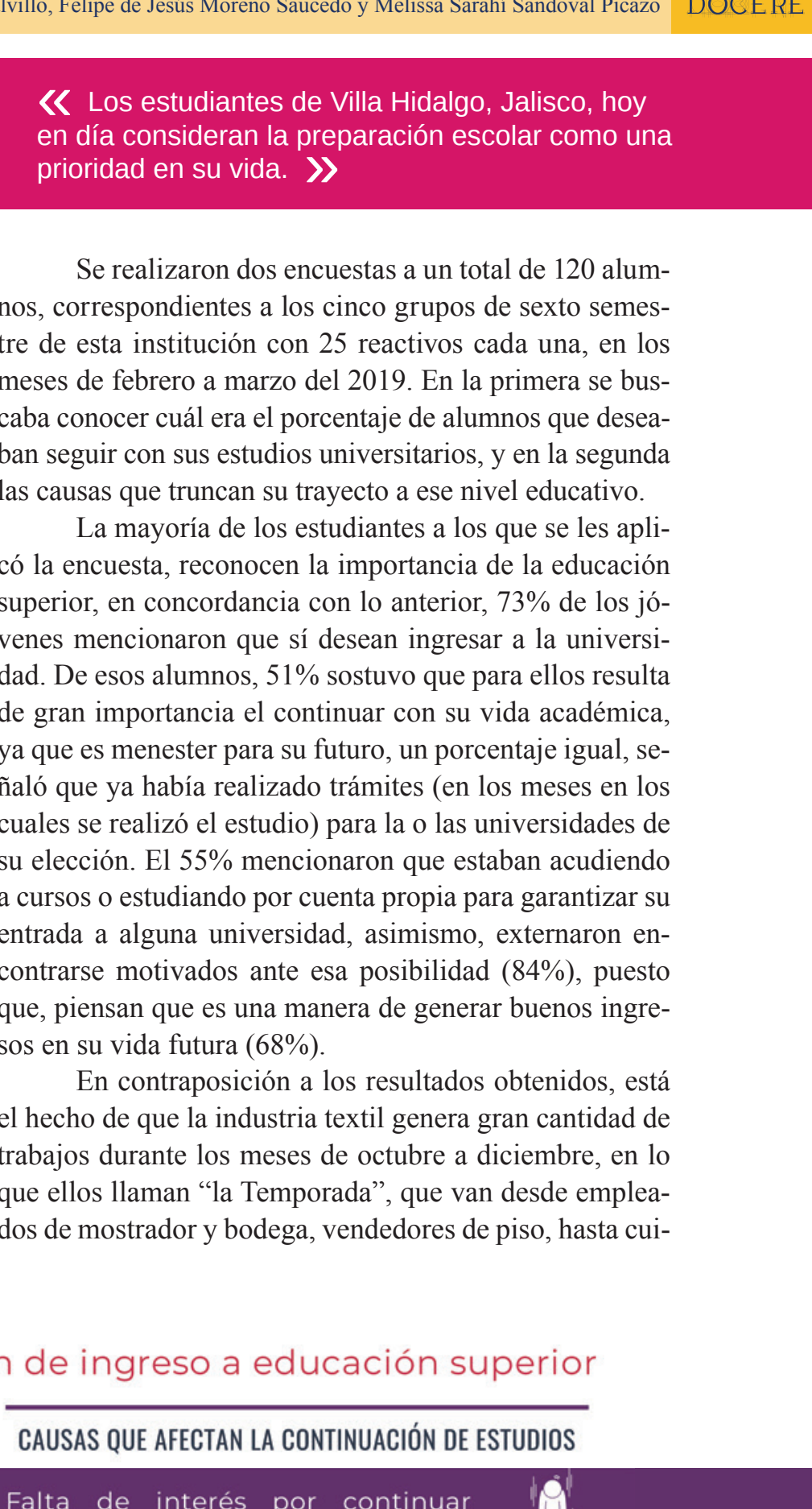

Falta de interés por continuar estudiando

Carencia de apoyo familiar

Recursos económicos insuficientes, que provocan que no se realice el trámite de admisión, sino que busquen:

- Oportunidades laborales temprana edad

- Alternativas fuera del país (migración) 
dadores de autos, etcétera. Los sueldos oscilan entre los quinientos y seiscientos pesos por sábado y domingo más comisiones, estos pagos, al ser jóvenes, representan un gran ingreso, por consiguiente, a ellos les parecen competitivos al no tener qué preocuparse por su manutención. Otro hecho que es importante recalcar es la alta tasa de migración de los habitantes de este municipio a los Estados Unidos, según los datos del IIEG (2018), Villa Hidalgo tiene un alto grado de migración y ocupa el $9^{\circ}$ lugar a nivel estatal en ese rubro.

En la segunda serie de cuestionamientos, relativos a las causas que condicionarían su ingreso a una institución de nivel superior, se obtuvo que los encuestados consideran que las razones que interrumpirían su instrucción académica serían: falta de interés $(62 \%)$, economía (33\%) y falta de apoyo familiar (5\%). En contraste con lo anterior, aunque los estudiantes perciben las razones anteriores como las principales, $72.89 \%$ señala que la razón fundamental para no continuar es que los recursos económicos con los que se cuentan no son los suficientes, por lo tanto, algunos de ellos deciden trabajar fines de semana o buscar trabajos de medio tiempo, aunado a lo anterior, muchos de los entrevistados pensaron en no realizar trámites de admisión (51\%).

\section{Conclusión}

El bachillerato es un proceso muy importante para la vida de cualquier estudiante, ya que en esta fase se forjan los ideales al futuro y la manera en la que se decide seguir preparándose para la vida. Los estudiantes de Villa Hidalgo, Jalisco, hoy en día consideran la preparación escolar como una prioridad en su vida, como lo muestran los resultados, y que es contrastante ya que anteriormente se observaba que la industria textil y los negocios familiares constituían las principales aspiraciones de la población estudiantil, después del bachillerato, además de la migración al país vecino. Actualmente los jóvenes de este lugar expresan sus deseos por seguir preparándose en el ámbito escolar, principalmente para la obtención de un mejor estatus económico y social, dejando de lado la visión en la cual se conforman con ser empleados.

\section{Fuentes de consulta}

Bustamante, Y. (2014). La educación media superior en México. Innovación Educativa, (14), 11-22. Consultado el 16 de enero del 2020, en http://bitly.ws/ahRY

Guerra, M. (2000). ¿Qué significa estudiar bachillerato? La perspectiva de los jóvenes en diferentes contextos socioculturales. Revista Mexicana de Investigación Educativa, (5), 243-272. Consultado el 21 de enero del 2020, en http://bitly.ws/ahS5

Ibarra, L., Escalante, A. y Fonseca, C. (2013). El significado de estudiar para los jóvenes de bachillerato. Archivos Analiticos de Politicas Educativas, 21(60), 1-28

IIEG. (2018). Villa Hidalgo. Diagnóstico del municipio, mayo 2018. Consultado el 09 de febrero del 2019, en https://bit.ly/2OleUDS

Ruiz, R., García, L. y Pérez, M. (2014). Causas y consecuencias de la deserción escolar en el bachillerato: Caso Universidad Autónoma de Sinaloa. Revista Ra Ximhai, 10(5), 51-74. Consultado el 15 de febrero del 2019, en http:// bitly.ws/ahS6

Sifuentes, G. y Lera, A. (2017). Estudio de factores motivacionales en estudiantes de nivel media superior de una escuela pública y privada: Estrategias para un mejor rendimiento académico a través de la motivación. Memorias del II Congreso sobre Desigualdad Social, Económica y Educativa en el Siglo XXI. Consultado el 20 de febrero del 2019, en http://bitly.ws/ahS9

Smulders C., M. (2018). Factores que influyen en la deserción de los estudiantes universitarios. ACADEMO Revista de Investigación en Ciencias Sociales y Humanidades 5(2), 127-132. Consultado el 1 de marzo del 2019, en http:// bitly.ws/ahS3

Valdez, E., Román, R., Cubillas, M., y Moreno, I. (2008). ¿Deserción o autoexclusión? Un análisis de las causas de abandono escolar en estudiantes de Educación Media Superior en Sonora, México. Revista Electrónica de Investigación Educativa, 10(1), 1-16. Consultado el 1 de marzo del 2019, en http://bitly.ws/ahSb 